\title{
Solitary mastocytoma presenting at birth
}

\author{
Non Hyeon $\mathrm{Ha}$, \\ Yoo Jung Lee, \\ Myong Chul Park, \\ II Jae Lee, \\ Sue Min Kim, \\ Dong Ha Park
}

Department of Plastic and Reconstructive Surgery, Ajou University Hospital, Suwon, Korea

\begin{abstract}
Mastocytosis is a rare disease which occurs in both children and adults, and it can manifest as a solitary or multiple skin lesions. Both can cause cutaneous or systemic symptoms. Because of the heterogeneity of clinical presentation of mastocytosis and its rare prevalence, it can be hard to suspect the mastocytosis at the first time. Most solitary mastocytomas are about $1-5 \mathrm{~cm}$ in diameter and have features of brownish-yellow, minimally elevated plaques with a smooth shiny surface. This article presents a case of solitary mastocytoma which occurred in neonate and that we treated through surgical excision. In histopathological examination, it consisted of c-kit-positive mast cells. Although pediatric cutaneous mastocytosis might regress spontaneously, clinicians should keep in mind that it could be associated with systemic mastocytosis which involves hematopoietic system.
\end{abstract}

Keywords: Mastocytoma / Cutaneous mastocytosis / Mast cells

\section{INTRODUCTION}

Mastocytosis is defined as a heterogenous group of disorders which show an increase in mast cell numbers as well as a typical histology in certain organs. Broadly, it is divided into cutaneous mastocytosis and systemic mastocytosis (SM) (Table 1). Cutaneous mastocytosis is subclassified into urticaria pigmentosa, maculopapular cutaneous mastocytosis, diffuse cutaneous mastocytosis, and mastocytoma of the skin [1]. SM is subclassified into indolent SM, SM with an associated hematologic neoplasm, aggressive systemic mastocytosis and mast cell leukemia. We present a case of SM of face in neonate that was treated with surgical excision successfully.

\section{CASE REPORT}

A 13-day-old neonate came to Ajou University Hospital with oval-shaped brownish skin lesion on her dorsum of nose (Fig. 1). At first, it was considered as a benign lesion, so we suggested her parents wait until she becomes tolerable to the general anesthesia

\section{Correspondence: Dong Ha Park}

Department of Plastic and Reconstructive Surgery, Ajou University Hospital, Ajou University School of Medicine, 164 World cup-ro, Yeongtong-gu, Suwon 16499, Korea E-mail: growhand@hanmail.net

Received September 7, 2017 / Revised March 13, 2018 / Accepted March 31, 2018 for removal. After 1 month, she came again to our clinic because the mass grew too fast (Fig. 2). We planned an excisional biopsy to rule out the malignancy. The size of the mass was $1.0 \mathrm{~cm} \times 0.6 \mathrm{~cm}$ (Fig. 3). After excision of the mass, histopathological examination revealed that the mass was a mastocytoma with c-kit-positive mast cells (Fig. 4). C-kit is a type transmembrane tyrosine receptor with an extracellular domain that binds to the mast cell growth factor (also known as steel factor or stem cell growth factor), which is responsible for growth, function and survival of mast cell [1]. The follow-up after surgical excision of the solitary mastocytoma was uneventful (Fig. 5). She didn't have any symptoms like flushing, pruritus, abdominal pain, nausea, vomiting, and diarrhea caused by mast cell activation and mast-cell derived mediator release. Although there's no abnormality on preopera-

Table 1. World Health Organization classification of mastocytosis

\begin{tabular}{|c|c|}
\hline Type of mastocytosis & Subtype \\
\hline $\begin{array}{l}\text { Cutaneous } \\
\text { mastocytosis }\end{array}$ & $\begin{array}{l}\text { Urticaria pigmentosa or maculopapular cutaneous } \\
\text { mastocytosis } \\
\text { Diffuse cutaneous mastocytosis } \\
\text { Mastocytoma of skin }\end{array}$ \\
\hline $\begin{array}{l}\text { Systemic } \\
\text { mastocytosis }\end{array}$ & $\begin{array}{l}\text { Indolent systemic mastocytosis } \\
\text { Systemic mastocytosis with an associated } \\
\text { hematologic neoplasm } \\
\text { Aggressive systemic mastocytosis } \\
\text { Mast cell leukemia }\end{array}$ \\
\hline
\end{tabular}




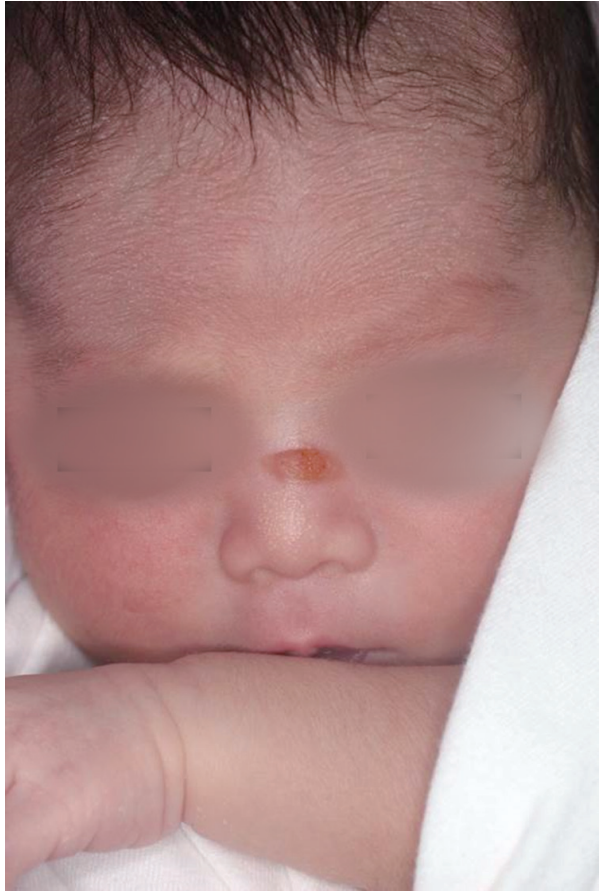

Fig. 1. Photograph of a 13-day-old neonate at the first visit of outpatient clinic. The size of the mass was $1 \mathrm{~cm} \times 0.3 \mathrm{~cm}$.



Fig. 2. One month after initial visit. The mass became wider and more protruding.

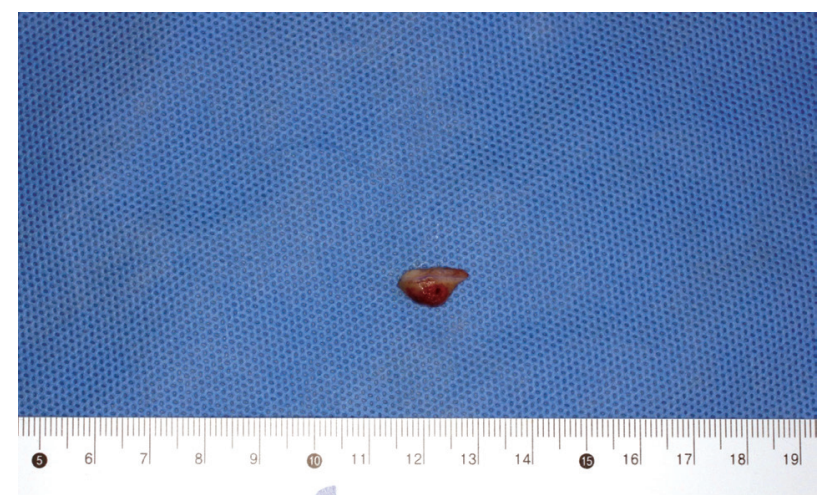

Fig. 3. Excisional biopsy was done. The size of the mass was $1.0 \mathrm{~cm} \times 0.6 \mathrm{~cm}$.

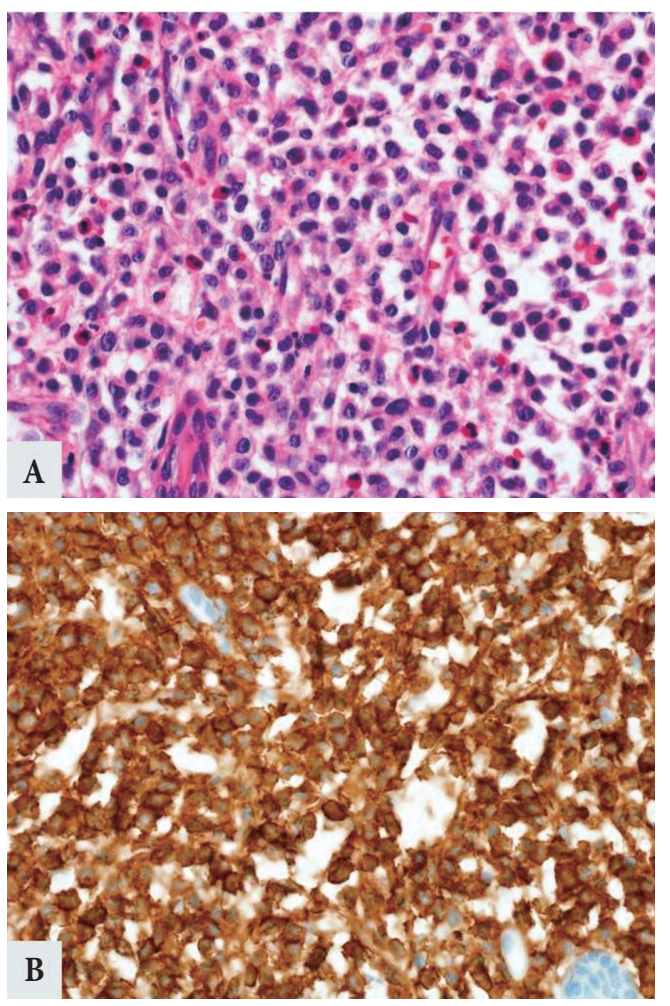

Fig. 4. Microscopic findings. (A) Infiltration of mast cells is present predominantly with eosinophils (H\&E, $\times 400)$. (B) An immunohistochemical stain directed against c-kit highlights the mast cell infiltrate (c-kit, $\times 400)$.

tive complete blood count, we referred to pediatrician of hematology for evaluating whether the bone marrow was involved and we confirmed that there was no systemic involvement. Because our impression was benign mass such as intradermal nevus or epidermal nevus, we didn’t check Darier's sign. Besides, rapid growing 


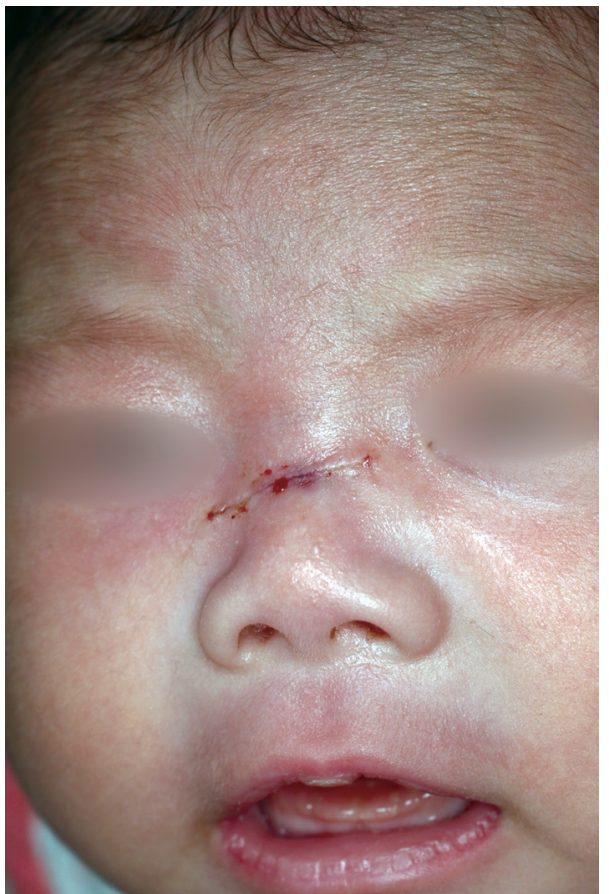

Fig. 5. Postoperative photograph of the patient. All stitch out was done.

nature of the mass made us think about malignant mass. Thus, we performed excisional biopsy instead of topical corticosteroid therapy. The patient was extremely young, even she was a 13-dayold neonate. And usually, in cutaneous mastocytosis, therapy is conservative care because the prognosis of cutaneous mastocytosis is good. But, in here, it seems that proper management was surgical excision rather than conservative care, in consideration of the rapid growing nature of the mass. In some cases, surgical removal of a solitary mastocytoma is effective treatment, and it offers a rapid and relatively clear outcome.

\section{DISCUSSION}

Mastocytosis is listed as a "rare disease" by the Office of Rare Diseases of the National Institutes of Health. The skin is the most frequently involved organ in mastocytosis. Among cutaneous mastocytosis, nodular cutaneous mastocytosis is rare manifestation of cutaneous mastocytosis [1]. Solitary mastocytoma accounts for $10 \%-15 \%$ of cutaneous mastocytosis [2] and it may be present at birth or appear within the first 3 months of life [3,4]. These lesions are either solitary or very few in number and present as plaques or nodules, larger than $1 \mathrm{~cm}$ in diameter usually on the extremities, but also in the face, scalp, and trunk. It can show the Darier's sign which consists of urtication and an axon flare. This form rarely has systemic involvement and systemic symptoms that are related with mast cell mediator release.

Clinical manifestation of mastocytosis is variable and it usually rests on the type of mastocytosis. Patients who have symptoms of mastocytosis, can present with pruritus, flushing, nausea, diarrhea, hepatosplenomegaly, lymphadenopathy, and anaphylaxis. Among those things, the most common symptom is pruritus.

Solitary mastocytoma has benign clinical course and self-limited. There are several provoking factors such as pressure, rubbing, emotional stress, intake of mast cell degranulating agents like aspirin, nonsteroidal anti-inflammatory drugs, codeine, opiates, and intravenous radiograph contrast fluids [5]. In symptomatic patients, oral $\mathrm{H1}$ and $\mathrm{H} 2$ antihistamines are commonly used and topical steroids should be used carefully because of their side effect.

Topical tacrolimus, a topical calcineurin inhibitors, was reported as a successful treatment of cutaneous mastocytoma in 18-month-old girl. They explained that its immunomodulatory effects on mast cell adhesion and the inhibition of the release of mediators from mast cells would work for the improvement of cutaneous mastocytoma [2].

SM is rare in children and accounts for less than $10 \%$ of pediatric mastocytosis cases. Children with SM usually have skin lesions similar to the patients with adult-onset disease, but also may have persistently elevated serum total tryptase, abnormalities on complete blood count and differential, hepatosplenomegaly, or rarely, unexplained lymphadenopathy. If there's a skin lesion with signs and symptoms suggestive of SM, do history and physical examination, laboratory tests to detect involvement of other organs, and biopsy of lesional skin $[6,7]$.

Symptoms of SM may be chronic or episodic. In progressive stages of the disease, mast cell end-organ damage causes weight loss and pathologic fractures and ascites may occur. While it has severe symptoms and poor prognosis, there's no curative therapy for SM. The treatment algorithm for SM is complex, and patient with advanced types should be referred to centers with expertise 
in SM. The mainstay of treatment of most categories of mastocytosis is H1-antihistamines and H2-antihistamines with the addition of corticosteroids for more severe symptoms. With advanced form, interferon $a$ and cladribine has shown considerable improvement in symptoms. The purpose of treatment is therefore to relieve symptoms and increase quality of life [7].

Mastocytosis also has malignant form which is called mast cell sarcoma. Mast cell sarcoma is an extremely rare type of mastocytosis, and it has aggressive nature and poor prognosis, regardless of several treatment modalities including various classic polychemotherapies, radiation therapy and surgical debulking. The median survival is only 12 months, and no good treatment is available [8].

In most cases of mastocytosis, due to their self-limited course, only yearly checkups are necessary and treatment is not required. However, in our case, the lesion had rapid-growing nature and was needed the pathologic confirmation to rule out the malignancy. We treated the solitary mastocytoma through surgical excision and there were no surgical complications or recurrence. Mastocytoma itself is considered as a benign condition, but we should keep in mind that there could be systemic manifestations and other organ involvements and then, that would be considered was a malignant condition. Despite good prognosis of solitary mastocytoma, surgical excision is considerable when it shows atypical features.

In the present case, there were no specific clinical findings for suspecting solitary mastocytoma. It is difficult to diagnose solitary mastocytoma because it is very rare disease and its clinical findings are nonspecific. Because solitary mastocytoma lacks specific presenting clinical features, it is important to cautiously examine the findings using a wide range of clinical tools to achieve an accurate histopathologic diagnosis.

In summary, we have herein reported a case of the solitary mastocytoma in a 13-day-old neonate, achieving early diagnosis and successful treatment. Considering that clinical diagnosis is very difficult in a solitary mastocytoma, early histopathologic diagnosis with high suspicion is crucial for early diagnosis and proper management.

\section{CONFLICT OF INTEREST}

No potential conflict of interest relevant to this article was reported.

\section{PATIENT CONSENT}

The patients provided written informed consent for the publication and the use of their images.

\section{REFERENCES}

1. Wolff K, Komar M, Petzelbauer P. Clinical and histopathological aspects of cutaneous mastocytosis. Leuk Res 2001;25:519-28.

2. Sukesh MS, Dandale A, Dhurat R, Sarkate A, Ghate S. Case report: solitary mastocytoma treated successfully with topical tacrolimus. F1000Res 2014;3:181.

3. Caplan RM. The natural course of urticaria pigmentosa: analysis and follow-up of 112 cases. Arch Dermatol 1963;87:146-57.

4. Chargin L, Sachs PM. Urticaria pigmentosa appearing as a solitary nodular lesion. AMA Arch Derm Syphilol 1954;69:345-55.

5. Heide R, Beishuizen A, De Groot H, Den Hollander JC, Van Doormaal JJ, De Monchy JG, et al. Mastocytosis in children: a protocol for management. Pediatr Dermatol 2008;25:493-500.

6. Abid A, Malone MA, Curci K. Mastocytosis. Prim Care 2016;43:50518.

7. UpToDate. Mastocytosis (cutaneous and systemic): evaluation and diagnosis in children [Internet]. Waltham, MA: UpToDate [cited 2018 Apr 4]. Available from: https://www.uptodate.com/contents/mastocytosis-cutaneous-and-systemic-evaluation-and-diagnosis-in-children.

8. Weiler CR, Butterfield J. Mast cell sarcoma: clinical management. Immunol Allergy Clin North Am 2014;34:423-32. 